\title{
Patent ductus arteriosus surgical ligation: Still a lot to understand
}

\author{
David Kalfa, MD, PhD, ${ }^{\mathrm{a}}$ Ganga Krishnamurthy, $\mathrm{MD},{ }^{\mathrm{b}}$ and Eva Cheung, $\mathrm{MD}^{\mathrm{c}}$
}

\footnotetext{
From the ${ }^{\mathrm{a}}$ Department of Pediatric Cardiac Surgery, ${ }^{\mathrm{b}}$ Division of Neonatalogy and Perinatology, and ${ }^{\mathrm{c}}$ Division of Pediatric Cardiology, Morgan Stanley Children's Hospital, NewYork-Presbyterian, Columbia University Medical Center, New York, NY.

Disclosures: Authors have nothing to disclose with regard to commercial support.

Received for publication April 3, 2016; accepted for publication April 4, 2016; available ahead of print May 6, 2016.

Address for reprints: David Kalfa, MD, PhD, Pediatric Cardiac Surgery, Morgan Stanley Children's Hospital, NewYork-Presbyterian, Columbia University Medical Center, New York, NY (E-mail: dk2757@cumc. columbia.edu).

J Thorac Cardiovasc Surg 2016;152:505-6

$0022-5223 / \$ 36.00$

Copyright (C) 2016 by The American Association for Thoracic Surgery

http://dx.doi.org/10.1016/j.jtcvs.2016.04.013
}

The article by McNamara's group from Toronto ${ }^{1}$ tries to identify possible pathogenic mechanisms contributing to oxygenation and ventilation failure after surgical ligation of hemodynamically significant patent ductus arteriosus (PDA).

Jain and colleagues ${ }^{2}$ are well known in this field for having described the postligation cardiac syndrome in this specific population and having demonstrated the benefits of an early postoperative prophylactic milrinone infusion to infants with a decreased left ventricular output. Despite this progress, some infants continue to experience postoperative respiratory deterioration. In the current article, ${ }^{1}$ the same group shows that preoperative diastolic dysfunction manifested by prolonged isovolumic relaxation time (IVRT) on a targeted postoperative neonatal echocardiogram may be associated with an adverse postoperative respiratory course. They postulate that the postoperative respiratory instability may relate to the inability of the premature left ventricle with a priori diastolic dysfunction to adapt to the postligation acute increase in left ventricular (LV) afterload leading to further augmentation in LV filling pressures and pulmonary venous hypertension, and thus provide an explanation for oxygenation failure.

This study has some limitations besides its retrospective nonrandomized nature and small sample size. The authors ${ }^{1}$ could not use oxygenation index as measurement of the primary end point of oxygenation failure because a large proportion of infants did not have a "true" arterial blood gas sample. Instead, they defined oxygenation failure as an increase in mean airway pressure or oxygen requirement from baseline by $20 \%$. Although this definition can be useful as a research end point, it may not be clinically relevant because deficits in oxygenation in most instances are overcome by transient increase in delivered oxygen or mean airway pressure. Moreover, the parameters of diastolic effects?

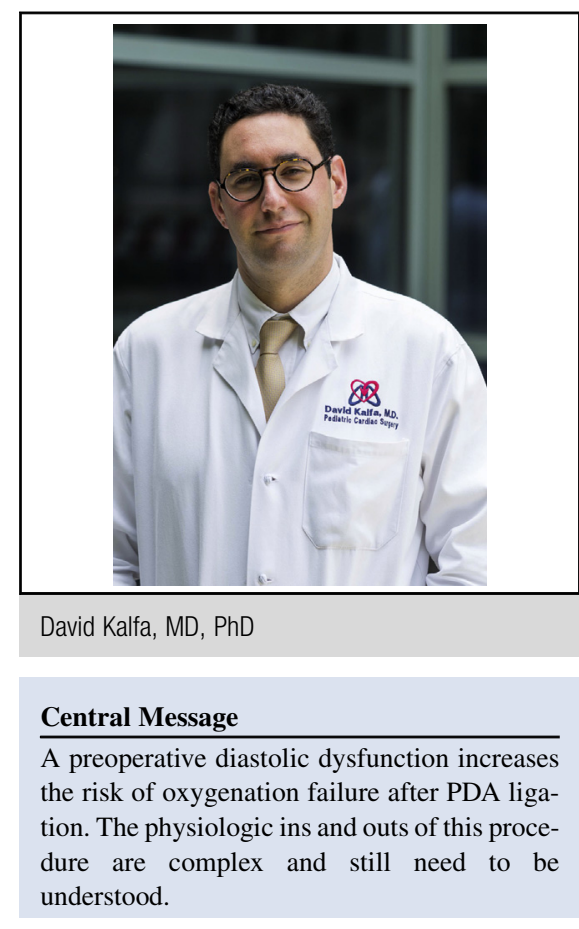

See Article page 498.

function were measured in only two thirds of infants, which limited their investigations of the risk factors contributing to postoperative instability. Finally, postoperative IVRT at 1 hour was not different between infants who experienced ventilation failure and those who did not. It may be that diastolic function deteriorates over time and that serial IVRT measurements in the immediate postoperative period capture the decline in diastolic function.

Despite these limitations, this article $^{1}$ is definitely of major interest and is hypothesis generating. Adequately powered, prospective studies are needed to determine whether LV diastolic dysfunction as measured by IVRT and $\mathrm{E} / \mathrm{A}$ ratio contributes to respiratory deterioration after PDA surgical ligation in premature infants. In such a case, will these infants benefit from a higher dose (than used in this study) of milrinone to exert its lusitropic

Prospective studies are needed to identify additional risk factors associated with both cardiac and respiratory instability among these infants (including contribution of adrenal insufficiency). Another area of precision medicine could focus on how to determine the most optimal timing 
of surgical PDA ligation, depending on the individual risk factors of each patient, potential association of PDA ligation with an increased risk of neurodevelopmental impairment, chronic lung disease and severe retinopathy of prematurity, ${ }^{3}$ and risks of waiting too long (prolonged exposure to the high-volume shunting, chronic myocardial ischemia secondary to coronary artery steal, and evolving bronchopulmonary dysplasia).

\section{References}

1. Ting JY, Resende M, More K, Nicholls D, Weisz DE, El-Khuffash A, et al. Predictors of respiratory instability in neonates undergoing patient ductus arteriosus ligation after the introduction of targeted milrinone treatment. J Thorac Cardiovasc Surg. 2016;152:498-504.

2. Jain A, Sahni M, El-Khuffash A, Khadawardi E, Sehgal A, McNamara PJ. Use of targeted neonatal echocardiography to prevent postoperative cardiorespiratory instability after patent ductus arteriosus ligation. J Pediatr. 2012;160:584-9.

3. Weisz DE, More K, McNamara PJ, Shah PS. PDA ligation and health outcomes: a 594 meta-analysis. Pediatrics. 2014;133:e1024-46. 